\title{
Máxima Fase Estável de Lactato em Ratos Obesos de Ambos os Gêneros
}

\author{
Maximal Lactate Steady State in Obese Rats of Both Genders
}

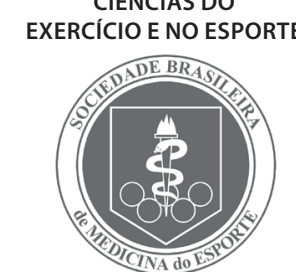

Artigo Original
Gustavo Gomes de Araujo Michel Barbosa de Araújo' Ricardo Antonio DAngelo' Fúlvia de Barros Manchado² Clécia Soares de Alencar Mota Carla Ribeiro

Maria Alice Rostom de Mello ${ }^{3}$

1. Mestrando em Educação Física pela Universidade Estadual Paulista - Rio Claro, SP - IB, Ciências da Motricidade.

2. Educadora Física, Mestre em Biodinâmica da Motricidade Humana, Universidade Estadual Paulista - Rio Claro, SP - IB.

3. Bióloga, Professora Doutora do Departamento de Educação Física da Universidade Estadual Paulista - Rio Claro, SP - IB.

Endereço para correspondência: Maria Alice Rostom de Mello, Av. 24 A, 1.515, Bela Vista, , Departamento de Educação Física, Unesp

- 13506-900 - Rio Claro,SP.

E-mail: mellomar@rc.unesp.br ou gusta ef@yahoo.com.br

Submetido em 04/09/2006

Versão final recebida em 08/01/2007 Aceito em 27/02/2007

\begin{abstract}
RESUMO
A incidência de obesidade vem crescendo entre a população mundial, levando a inúmeras complicaçõe,s como risco de doenças crônico-degenerativas. Por outro lado, o exercício físico tem sido empregado isoladamente ou em associação a dieta, no tratamento dessa doença. Assim, pesquisas envolvendo exercício são imprescindíveis para evolução no tratamento e controle da obesidade. O objetivo deste estudo foi identificar a intensidade de exercício equivalente à transição metabólica aeróbio-anaeróbia em ratos Wistar obesos de ambos os gêneros, por tratamento com glutamato monossódico (MSG), utilizando o protocolo de máxima fase estável de lactato (MFEL). Para isso, foram testados 40 ratos adultos subdivididos em quatro grupos com 10 animais cada um: controle machos, controle fêmeas, obeso machos e obeso fêmeas. Depois de adequada adaptação (três semanas) ao exercício em meio líquido $\left(31 \pm 1^{\circ} \mathrm{C}\right)$ os animais foram submetidos a teste de natação ( $25 \mathrm{~min}$ ) suportando sobrecargas contínua e aleatória correspondentes a 4,5 - 5,0 - 5,5-6,0 e 6,5\% do peso corporal (PC), com intervalo de 72 horas entre elas. Os animais dos grupos obesos tiveram aumentos no peso do tecido adiposo subcutâneo, mesentérico e retroperitonial em relação aos grupos controle. O índice de Lee foi maior nos animais obesos em comparação com os controles. Foi possível identificar a MFEL a 6,0\% do PC nos dois grupos obesos. Para o grupo controle fêmea, a MFEL esteve por volta de 5,0\% do PC enquanto que nos controle macho a 4,5\% do PC. Desse modo pode-se concluir que a obesidade induzida por MSG interfere na cinética de lactato durante o exercício em ambos os sexos, alterando a intensidade de esforço referente à transição metabólica.
\end{abstract}

Palavras-chave: obesidade, capacidade aeróbia, hipotálamo.

\begin{abstract}
The purpose of this study was to identify the exercise intensity equivalent to the aerobic/anaerobic metabolic transition in obese rats of both genders using the maximal lactate steady state (MLSS) protocol. Four groups of rats were tested on MLSS protocol (swimming exercise): male control $n=10$, female control $n=10$, male obese $n=10$ and female obese $n=10$, after suitable adaptation to exercise in liquid medium and obesity induction by monossodic glutamate (MSG) administration. The obese groups had significant increase in subcutaneous adipose tissue as well as mesenteric and retroperitoneal fat depots comparing to the control groups. The Lee index was higher in the obese animals in comparison to their respective controls. It was possible to identify the MLSS at $6.0 \%$ of body weight for both obese groups. Concerning the female control group, the MLSS was determined at the intensity of $5.0 \%$ of body weight, whereas for the male control at $4.5 \%$ of body weight. It was concluded that obesity induced by MSG interferes in lactate kinetics during exercise and alters the effort intensity corresponding to the metabolic transition in both genders.
\end{abstract}

Keywords: obesity, aerobic capacity, hypothalamus.

\section{INTRODUÇÃO}

A obesidade é provavelmente uma das enfermidades mais antigas que acometem o homem e, talvez, seja a situação mais complexa e de difícil entendimento, tanto no meio científico como entre leigos. É definida como um acúmulo excessivo de gordura corporal, caracterizada não só pelo aumento de peso corporal, mas também pelo aumento excessivo de massa adiposa depositada em vários compartimentos corporais ${ }^{(1)}$. O número de pessoas portadoras de sobrepeso e obesidade vem aumentado de forma significativa no Brasil e no mundo. Segundo a Organização Mundial de Saúde (OMS), o número de obesos entre 1995 a 2000 passou de 200 para 300 milhões, perfazendo 15\% da população mundial. Estimativas mostram que, em 2025, o Brasil será o quinto país do mundo com maior incidência de obesidade em sua população(2).

A obesidade pode resultar de fatores endógenos, que representam $5 \%$ ou menos dos casos, incluindo fatores hereditários, congênitos, psicogênicos, neurológicos e endócrinos. Os fatores exógenos, que representam cerca de 95\% dos casos, estão relacionados a fatores ambientais, principalmente hipoatividade física e maus hábitos alimentares ${ }^{(2)}$. Por essa razão, o exercício físico tem sido empregado isoladamente ou em associação com a dietoterapia, na promoção da perda de peso e na manutenção de níveis lipidêmicos normais.
Pesquisas envolvendo exercício e obesidade são imprescindíveis para evolução no tratamento e controle dessa doença. Nesse sentido, a utilização de modelos experimentais pode ser de extrema utilidade, tornando possíveis avaliações com maior controle e precisão. Desse modo, vários modelos de obesidade animal têm sido analisados e já foram classificados pela sua etiologia. Entre os modelos neurais, a obesidade hipotalâmica é a mais conhecida(3). Pode ser promovida por várias maneiras, incluindo as injeções sistêmicas de glutamato monossódico (MSG) ${ }^{(4,5)}$. Contudo, o emprego de modelos animais nos estudos que envolvem o exercício é comprometido pela dificuldade na identificação da intensidade do esforço. Recentemente, em nossos laboratórios, foram desenvolvidos protocolos que possibilitaram a identificação da intensidade de exercício correspondente à transição metabólica aeróbio-anaeróbia durante o exercício em ratos ${ }^{(6-8)}$. Nesses estudos, foram descritos protocolos onde a identificação da transição metabólica em ratos eutróficos durante o exercício de natação foi efetuada através da determinação da máxima fase estável de lactato MFEL ${ }^{(6)}$ bem como do limiar anaeróbio (Lan), utilizando-se o teste de lactato mínimo ${ }^{(7,8)}$. A MFEL é considerada a mais alta concentração sanguínea de lactato, durante o exercício com cargas constantes na 
qual a entrada do substrato na circulação iguala a remoção, sendo um importante indicador da capacidade aeróbia tanto em humanos quanto em ratos ${ }^{(6,9,10)}$. A intensidade de exercício correspondente à MFEL requer predominância do sistema energético aeróbio. Acima dessa intensidade, o predomínio energético desloca-se para as vias anaeróbias

Conhecendo-se as diferenças endócrino-metabólicas entre os gêneros, é plausível supor que também possa haver distinções na intensidade de esforço equivalente à transição aeróbio-anaeróbia determinada durante o exercício. Dessa forma, o objetivo do presente estudo foi delineado para identificar a intensidade de exercício equivalente à transição metabólica de ratos obesos de ambos os gêneros. Especificamente, visou-se estabelecer carga de esforço e concentrações sanguíneas de lactato individuais correspondentes à transição metabólica de ratos eutróficos e obesos, de ambos os gêneros, pela administração de glutamato monossódico, durante exercício de natação, pelo protocolo de MFEL.

\section{MÉTODOS}

\section{Animais e seu tratamento}

Todos os experimentos seguiram as resoluções brasileiras específicas de bioética de pesquisa com animais: lei 6,638, de 8 de março de 1979 e decreto 645, de 10 de julho de 1945.

Foram utilizados ratos de ambos os gêneros, da linhagem Wistar, recém-nascidos. Após o desmame, os mesmos foram mantidos em gaiolas coletivas de polietileno, medindo 37,0 X31,0 × 16,0 cm, (cinco animais por gaiola) sob condições de temperatura $\left(25^{\circ} \mathrm{C}\right)$ e ciclo claro/escuro (12h/12h) controlados. Os ratos tiveram livre acesso à água e alimentação (ração comercial para roedores).

\section{Delineamento e grupos experimentais}

Os animais recém-nascidos de ambos os gêneros foram separados em quatro grupos: controle machos (CM): receberam solução fisiológica ( $\mathrm{NaCl}$ 0,9\%) via subcutânea, a cada dois dias, nos primeiros 14 dias de vida $(n=10)$; controle fêmeas (CF): receberam solução fisiológica ( $\mathrm{NaCl}$ 0,9\%) via subcutânea, a cada dois dias, nos primeiros 14 dias de vida $(n=10)$; obeso machos (OM): receberam glutamato monossódico via subcutânea (4,0mg/g de peso corporal - PC), a cada dois dias nos primeiros 14 dias de vida, para indução da obesidade ${ }^{(4,5)}$ $(n=10)$; obeso fêmeas (OF): receberam glutamato monossódico via subcutânea, (4,0mg/g de PC), a cada dois dias nos primeiros 14 dias de vida, para indução da obesidade ${ }^{(3)}(n=10)$.

\section{Adaptação ao meio líquido}

A partir de 60 dias de idade, os ratos foram adaptados ao meio líquido $\left(31 \pm 1^{\circ} \mathrm{C}\right)$ por três semanas, em tanques individuais profundos (120 x $60 \mathrm{~cm}$ ). A partir da $2^{\mathrm{a}}$ semana de adaptação, os animais suportaram sobrecargas de aproximadamente $2 \%$ do peso corporal (PC).

\section{Máxima fase estável de lactato (MFEL)}

A MFEL foi determinada através da adaptação do protocolo aplicado por Gobatto et al. ${ }^{(6)}$ com cargas constantes equivalentes a 4,5-5,0 - 5,5 - 6,0 e 6,5\% do PC, distribuídas de forma aleatória e com intervalos de 72 horas entre elas. Houve coleta de sangue da extremidade distal da cauda em repouso e a cada cinco minutos de exercício para dosagem de lactato, por analisador eletroquímico (Yellow Sport Instruments $1500^{\circledR}$ ).

\section{Avaliações realizadas na condição de repouso, antes do sacrifício}

O índice de Lee foi calculado para todos os animais pela divisão da raiz cúbica do peso corporal em gramas (g) pelo comprimento focinho-ânus em centímetros ( $\mathrm{cm}$ ) e multiplicando-se por 10 $0^{(11)}$. Esse índice, proposto para animais experimentais, equivale ao índice de massa corporal (IMC) obtido para humanos ${ }^{(11)}$.

\section{Avaliações realizadas na condição de repouso após o sacrifício}

Os animais foram sacrificados 72 horas após os testes para excisão total do tecido adiposo das regiões subcutânea, mesentérica e retroperitonial, para pesagem em balança analítica e dosagem da concentração de lipídios totais ${ }^{(5)}$.

\section{Análise estatística}

Os dados foram expressos em média \pm desvio padrão. Foi utilizada análise de variância (ANOVA - one way) e quando necessário foi aplicado teste post-hoc de Newman-Keuls para a comparação entre os grupos. O nível de significância foi prefixado em 5\% (Statistica 5.0\%).

\section{RESULTADOS}

\section{Parâmetros somáticos}

A tabela 1 descreve os resultados de ganho de peso (g), comprimento corporal $(\mathrm{cm})$ e índice de Lee. Com relação ao ganho de peso, as fêmeas (CF e OF) apresentaram menor ganho em comparação com o grupo OM. O grupo OF apresentou comprimento corporal menor comparado com os grupos OM e CM e maior em relação ao CF. O índice de Lee foi superior nos grupos obesos (OF e OM) em comparação com os controles correspondentes.

Tabela 1. Ganho de peso (g), comprimento corporal (cm) e índice de Lee (raiz cúbica do peso corporal/ comprimento corporal x 10) dos animais

\begin{tabular}{|c|c|c|c|c|}
\hline & OM $(n=10)$ & CM $(n=10)$ & OF $(n=10)$ & $\mathrm{CF}(n=10)$ \\
\hline Ganho de peso & $65,5 \pm 13,5$ & $58,5 \pm 15,3$ & $47,2 \pm 19,2^{\mathrm{a}}$ & $34,6 \pm 9,31^{a, *}$ \\
\hline Comprimento corporal & $24,4 \pm 0,4^{\#}$ & $22,6 \pm 0,9$ & $20,6 \pm 0,6^{*,, t, a}$ & $19,2 \pm 0,7$ \\
\hline Îndice de Lee & $334,0 \pm 16,1^{17}$ & $319,8 \pm 13,4$ & $326,0 \pm 14,7^{*}$ & $308,7 \pm 6,7^{a, b, b}$ \\
\hline
\end{tabular}

O peso do tecido adiposo das regiões mesentérica, retroperitonial e subcutânea apresentou valores maiores nos grupos obesos de ambos os gêneros. $O$ teor de lipídios do tecido adiposo mesentérico foi maior nos grupos obesos (OM e OF) que nos controles (CM e CF) (tabela 2).

Tabela 2. Peso do tecido adiposo (g) e teores de gordura ( $\mathrm{mg} / 100 \mathrm{mg}$ ) do tecido adiposo subcutâneo, mesentérico e retroperitonial nos grupos controle macho (CM), obeso macho (OM), controle fêmea (CF) e obeso fêmea (OF)

\begin{tabular}{l|c|c|c|c}
\hline & & Subcutânea & Mesentérico & Retroperitonial \\
\hline $\mathrm{CM}(n=10)$ & Peso & $3,4 \pm 0,7$ & $2,6 \pm 1,2$ & $2,7 \pm 0,7$ \\
\hline & Teor & $84,2 \pm 13,2$ & $68,7 \pm 13,3$ & $106,3 \pm 20,6$ \\
\hline $\mathrm{OM}(n=10)$ & Peso & $9,1 \pm 3,1^{\#, *}$ & $5,7 \pm 1,8^{\#, *}$ & $5,7 \pm 2,7^{\#,{ }^{*}}$ \\
\hline & Teor & $78,3 \pm 15,1$ & $109,2 \pm 33,5^{\#, b}$ & $87,2 \pm 15,6^{\#}$ \\
\hline $\mathrm{CF}(n=10)$ & Peso & $2,0 \pm 0,7$ & $1,6 \pm 0,5$ & $1,4 \pm 0,4$ \\
\hline & Teor & $101,0 \pm 50,1$ & $76,4 \pm 19,2$ & $59,5 \pm 13,4^{\#, a}$ \\
\hline $\mathrm{OF}(n=10)$ & Peso & $9,5 \pm 4,1^{\#, *}$ & $4,6 \pm 2,3^{\#, *}$ & $3,9 \pm 1,1^{\#, *, a}$ \\
\hline & Teor & $75,5 \pm 11,5$ & $97,9 \pm 35,2^{\#, *}$ & $61,5 \pm 16,4^{\#, a}$ \\
\hline
\end{tabular}

\# Diferença significativa em relação ao controle macho (CM). P $<0,05$

* Diferença significativa em relação ao controle fêmea (CF). P $<0,05$

a Diferença significativa em relação ao obeso macho (OM). $P<0,05$

${ }^{b}$ Diferença significativa em relação ao obeso fêmea (OF). P $<0,05$

Para os ratos pertencentes ao grupo controle macho (CM), a máxima fase estável de lactato (MFEL) ocorreu na intensidade equivalente a 4,5\% do PC em $40 \%$ dos animais testados, à concentração média de lactato de 6,37 $\pm 0,37 \mathrm{mM}$. Para esses ratos, nos testes com cargas superiores, não houve estabilização das concentrações de lactato sanguíneo durante o teste. A figura 1 mostra os valores lactacidêmicos de um animal pertencente ao grupo CM durante os testes suportando sobrecargas de 4,5 - 5,0 - 5,5-6,0 e 6,5\% do PC. Os demais animais apresentaram MFEL nas intensidades equivalentes a 5,0\% (20\%) e 5,5\% (30\%) do PC, às concentrações de $8,50 \pm 1,04$ e 7,52 $\pm 1,57 \mathrm{mM}$ de lactato sanguíneo. Nos animais restantes (10\%) não foi possível a determinação da MFEL.

Para 60\% dos animais do grupo obeso macho a MFEL foi obtida na intensidade equivalente a $6 \%$ do peso corporal. A concentração média de lactato sanguíneo entre os minutos 10, 15, 20 e 25 não variou \pm $1 \mathrm{mM}$, tendo valores médios de 5,67 $\pm 0,24 \mathrm{mM}$. Para esses animais, nos testes com as cargas equivalentes a 4,5-5,0 e 5,5\% do PC, houve estabilização da concentração sanguínea de lactato em valores menores. No teste com carga de 6,5\% do PC houve aumento do lactato sanguí- 


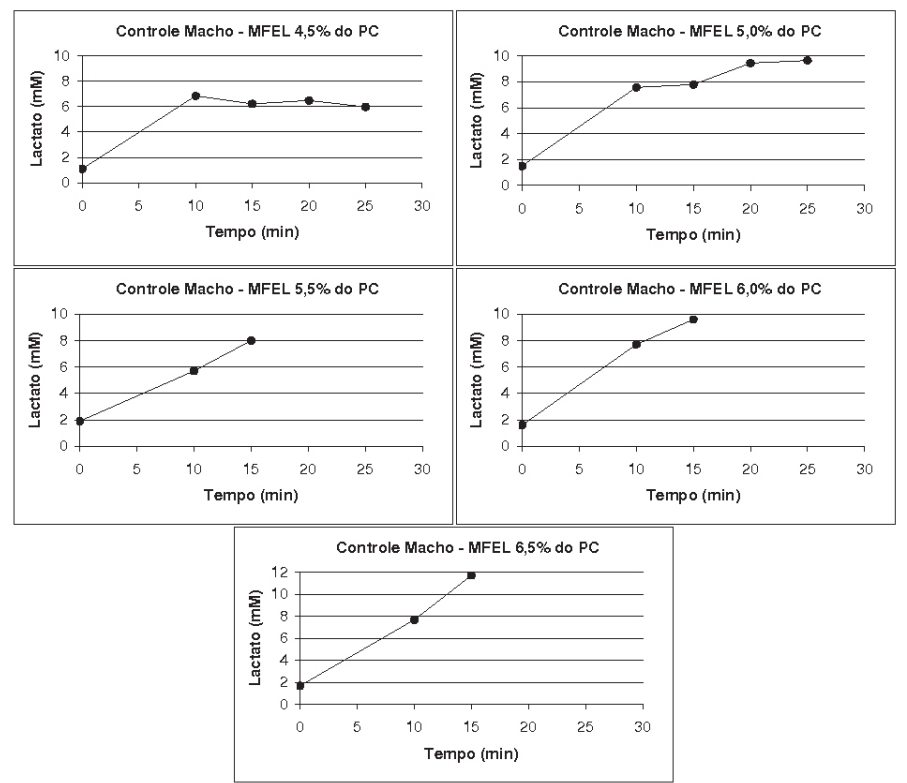

Figura 1. Lactacidemia ( $\mathrm{mM}$ ) em repouso e aos $10^{\circ}, 15^{\circ}, 20^{\circ}$ e $25^{\circ} \mathrm{min}$ de exercício em um rato do grupo controle macho (CM) durante testes de natação suportando cargas constantes de 4,5-5,0-5,5-6,0 e 6,5\% do peso corporal, visando a determinação da máxima fase estável de lactato (MFEL). MFEL determinada a 4,5\% do PC.

neo ao longo do teste. A figura 2 mostra as concentrações de lactato sanguíneo de um animal do grupo OM durante os testes suportando as sobrecargas de $4,5-5,0-5,5-6,0$ e 6,5\% do PC. Para os demais animais do grupo OM, a MFEL foi assim determinada: $20 \%$ dos animais em $5,5 \%$ do PC e $20 \%$ dos animais em $6,5 \%$ do PC às concentrações médias de lactato sanguíneo de 4,77 $\pm 0,27$ e 6,90 $\pm 1,89 \mathrm{mM}$.

No grupo controle fêmea (CF) a MFEL foi determinada na intensidade de 5,0\% do PC em 70\% dos animais avaliados. O valor médio da lactacidemia nessa carga foi de 7,88 $\pm 0,17$. Para esses animais, no teste com as cargas equivalentes a 4,5\% do PC, houve estabilização das concentrações sanguíneas de lactato em valores menores. Nas demais cargas (5,5- 6,0 e 6,5\% do PC), houve aumento constante das concentrações de lactato sanguíneo ao longo dos testes. A figura 3 mostra os valores de lactato sanguíneo de um animal do grupo CF durante os testes suportando as sobrecargas de 4,5-5,0-5,5-6,0 e $6,5 \%$ do PC. Para os demais animais a MFEL foi obtida nas cargas de $4,5 \%$ do PC (20\%) e 5,5\% do PC (10\%) com valores lactacidêmicos médios de $5,35 \pm 0,77$ e 7,61 $\pm 1,86$
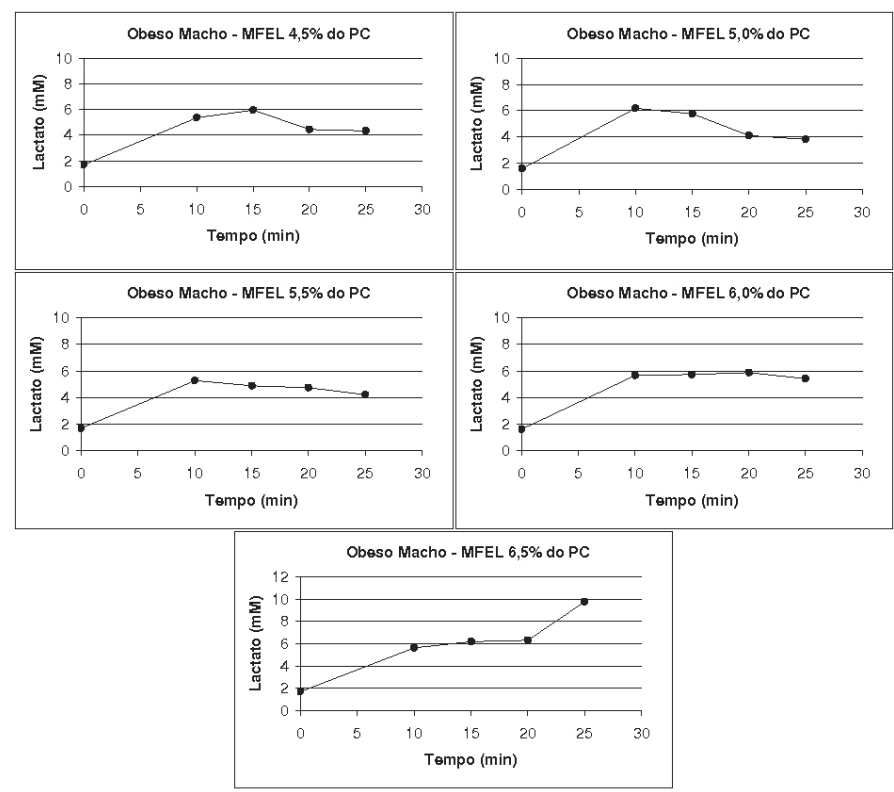

Figura 2. Lactacidemia ( $\mathrm{mM}$ ) em repouso e aos $10^{\circ}, 15^{\circ}, 20^{\circ}$ e $25^{\circ}$ min de exercício em um rato do grupo obeso macho (OM) durante testes de natação suportando cargas constantes de 4,5 - 5,0 - 5,5- 6,0 e 6,5\% do peso corporal, visando a determinação da máxima fase estável de lactato (MFEL). MFEL determinada a 6,0\% do PC.
Os resultados de lactacidemia para o grupo obeso fêmea (OF) mostraram que a MFEL foi encontrada na intensidade de 6,0\% do PC em 50\% dos animais avaliados (figura 4). Os animais restantes tiveram MFEL nas intensidades de 4,5\% (10\% dos animais), 5,5\% (10\% dos animais) e 6,5\% (20\% dos animais). As concentrações médias de lactato $(\mathrm{mM})$ para o grupo OM foram de: $3,38 \pm 0,59$ (4,5\% do PC), 3,97 $\pm 1,22$ (5,0\% do PC), 4,59 $\pm 0,24$ (5,5\% do PC), 4,89 $\pm 0,41$ (6,0\% do PC) e 5,11 \pm (6,5\% do PC).

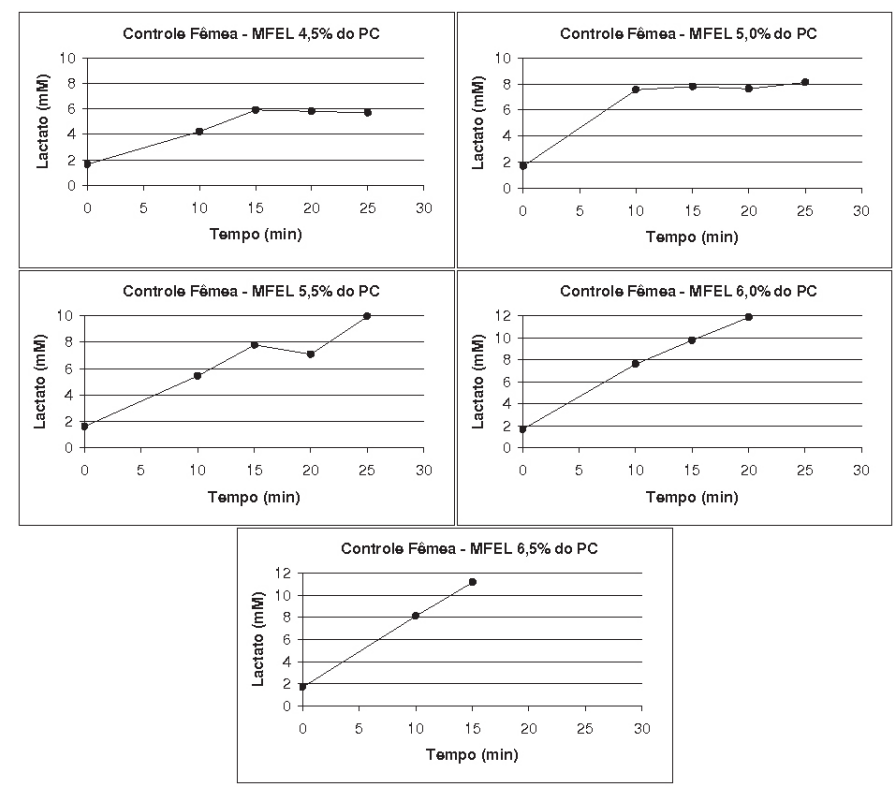

Figura 3. Lactacidemia (mM) em repouso e aos $10^{\circ}, 15^{\circ}, 20^{\circ}$ e $25^{\circ}$ min de exercício em um rato do grupo controle fêmea (CF) durante testes de natação suportando cargas constantes de 4,5 - 5,0 - 5,5-6,0 e 6,5\% do peso corporal, visando a determinação da máxima fase estável de lactato (MFEL). MFEL determinada a 5,0\% do PC.

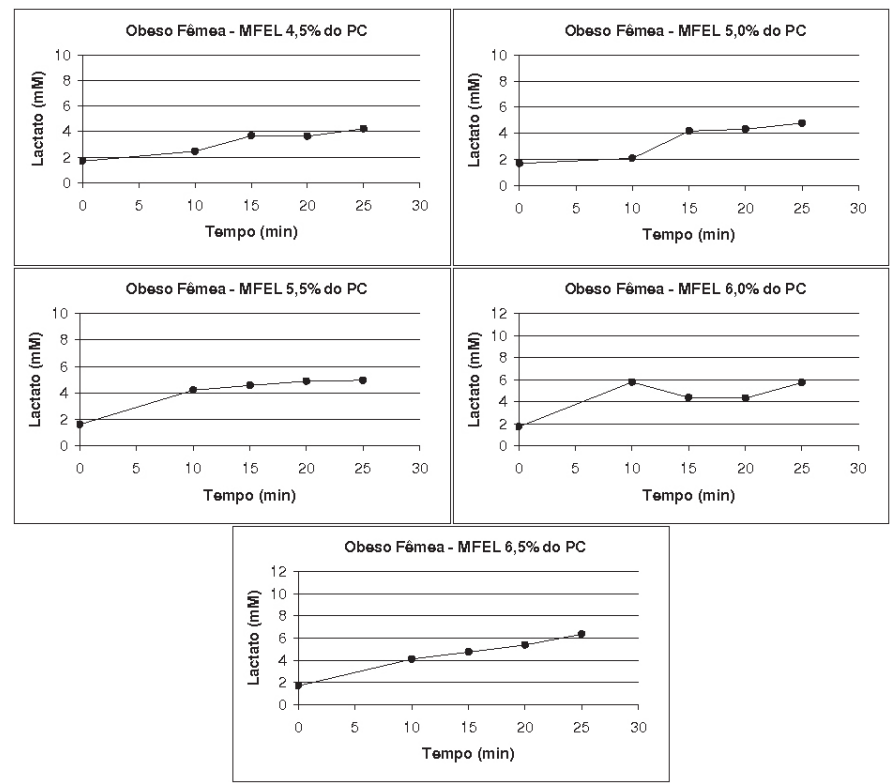

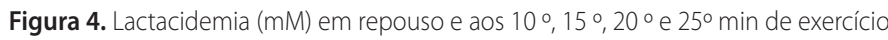
em um rato do grupo obeso fêmea (OF) durante testes de natação suportando cargas constantes de 4,5 - 5,0 - 5,5 - 6,0 e 6,5\% do peso corporal, visando a determinação da máxima fase estável de lactato (MFEL). MFEL determinada a 6,0\% do PC.

\section{DISCUSSÃO}

A incidência de obesidade vem aumentando significativamente entre a população mundial, causando inúmeros problemas de saúde como riscos cardíacos, diabetes mellitus, hipertensão arterial, entre outras doenças crônico-degenerativas, tanto em homens quanto em mulheres ${ }^{(12)}$. No entanto, os fatores de risco entre homens e mulheres são distintos devido a diversos fatores, incluindo a deposição da gordura corporal em diferentes áreas corporais ${ }^{(13-15)}$. Freedman et al. ${ }^{(13)}$, verificaram que homens possuem maior tendência de acúmulo de gordura nas regiões central visceral enquanto nas mulheres esse aumento localiza-se nas extremidades. 
No presente estudo verificou-se que teor e peso lipídico das regiões mesentérica, subcutânea e retroperitonial foram maiores nos grupos induzidos à obesidade (OM e OF) em relação aos respectivos controles. Além disso, as concentrações de lipídios no tecido adiposo mesentérico foram superiores nos grupos obesos (OM e OF) em comparação com os correspondentes controles (CM e CF). Entre os machos, o inverso ocorreu no tecido adiposo retroperitonial. Esses dados demonstram as diferenças associadas ao gênero na distribuição das reservas adiposas nos animais do presente estudo.

A eficácia na indução da obesidade pelo tratamento com MSG foi evidenciada especialmente pelo aumento no peso do tecido adiposo das diferentes regiões analisadas. Isso se deve à conhecida ação lesiva do MSG aos núcleos hipotalâmicos de roedores, danificando áreas do sistema nervoso central e ocasionando diminuição do metabolismo basal ${ }^{(3,16,17)}$. Como conseqüência, o índice de Lee foi estatisticamente maior nos grupos obesos de ambos os gêneros em relação aos correspondentes controles.

Sabe-se que a atividade física desempenha um importante papel na prevenção e tratamento da obesidade, quando prescrita de maneira controlada e específica para cada público-alvo ${ }^{(18,19)}$. Por essa razão, pesquisas envolvendo exercício são imprescindíveis tanto em humanos quanto em modelos experimentais ${ }^{(5,15,18)}$. No entanto, dos trabalhos que utilizam a atividade física em cobaias de laboratório, especialmente ratos, poucos se preocupam em monitorar e determinar a intensidade de esforço do animal durante o exercício. Isso indica a necessidade de estudos que visem desenvolver metodologias viáveis para determinação das capacidades aeróbia e anaeróbia desses animais.

Nesse sentido, Gobatto et al.(20) realizaram teste incremental de natação submetendo um grupo de ratos eutróficos e sedentários a quatro testes progressivos com duração de cinco minutos em intensidades de 0, 5, 8 e 13\% do PC. Após cada estágio amostras sanguíneas foram coletadas para determinação do lactato sanguíneo. Infelizmente, esses autores não verificaram o comportamento clássico de lactacidemia e conseqüentemente não encontraram a intensidade referente ao limiar anaeróbio dos ratos.

Em outro estudo, Gobatto et al. ${ }^{(6)}$ submeteram um grupo de ratos sedentários a 20 minutos de natação com cargas contínuas equivalentes a 5, 6, 7, 8, 9 e 10\% do peso corporal, distribuídas aleatoriamente com coletas de amostras sanguíneas a cada cinco minutos. Foi observada estabilização do lactato sanguíneo na concentração de 5,5mM, nas cargas de 5 e 6\% do PC. Além disso, constataram, após nove semanas de treinamento aeróbio, estabilização da lactacidemia na mesma concentração observada ao início do estudo $(5,5 \mathrm{mM})$, porém com carga correspondente a 8\% do PC. Esse estudo, além de demonstrar a possibilidade de determinação da capacidade aeróbia de ratos, evidenciou a sensibilidade desse método aos efeitos do treinamento em ratos comuns. O conjunto de informações contidas nesses estudos indica que é viável a estimativa da intensidade do esforço equivalente à transição metabólica aeróbio-anaeróbia durante exercício em ratos, por protocolos similares aos aplicados para a avaliação de seres humanos.

Braga et al.(23) buscaram identificar a resposta do exercício físico durante programas de treinamento continuo e intermitente em ratos obesos submetidos ao tratamento com MSG. Verificaram que a ati- vidade física reduziu os teores de gordura da carcaça em ambos os treinamentos. Contudo, nesse estudo não houve a preocupação em individualizar a carga ideal de treinamento em ratos obesos.

Voltarelli et al. ${ }^{(8)}$ adaptaram o teste de lactato mínimo proposto por Tegtbur et al. ${ }^{(21)}$ para seres humanos a ratas obesas por tratamento com MSG e determinaram a capacidade aeróbia nesses animais de maneira individualizada. Por outro lado, devido à característica extenuante do teste de lactato mínimo durante a indução da lactacidemia, o protocolo parece muito agressivo para as condições físicas dos animais tratados com MSG. Mesmo assim, os autores verificaram que, para uma mesma carga de trabalho, os animais obesos realizaram menor esforço em comparação com o grupo controle(22).

Os achados de Voltarelli et al. ${ }^{(8)}$ corroboram os dados do presente estudo, no qual a MFEL encontrada nos grupos obesos, macho e fêmea, foi mais elevada (6\% do PC) que nos grupos controles: $5 \%$ do PC para as fêmeas e 4,5\% para os machos. Esse fenômeno pode ser explicado, em parte, pela menor densidade corporal apresentada por ratos obesos pelo tratamento com MSG ${ }^{(8)}$. Isso pode facilitar a flutuação durante o exercício de natação explicando uma redução na intensidade de esforço.

Cabe ainda destacar que, no grupo controle macho, a intensidade de esforço equivalente à MFEL diferiu daquela encontrada por Gobatto et al.(6) (5-6\% do PC). Contudo, o ergômetro utilizado nesse estudo foi coletivo e com menor profundidade em comparação com o do estudo de Gobatto et al. (6).

Assim sendo, os presentes resultados mostram-se bastante promissores para a identificação de carga de esforço e concentrações sanguíneas de lactato individuais correspondentes à transição metabólica de ratos tanto eutróficos quanto obesos, de ambos os gêneros, durante exercício de natação. Contudo, deve-se ressaltar que o protocolo de MFEL apresenta algumas limitações, como necessidade de realização de vários testes, consumindo diversos dias, além de incluir processos invasivos. Por essas razões, encontram-se em andamento em nossos laboratórios estudos visando desenvolvimento tanto de protocolos não invasivos quanto protocolos envolvendo menor número de testes, o que, sem dúvida, vai otimizar os procedimentos para avaliação de ratos durante o exercício.

Em resumo, podemos concluir que no presente estudo foi possível estabelecer precisamente a carga de esforço equivalente à transição metabólica de ratos obesos. Além disso, o protocolo adotado foi capaz de respeitar o princípio da individualidade na avaliação dos animais. Isso implica a possibilidade de minimização de erros na prescrição de um programa de treinamento físico para o controle da obesidade, em modelo experimental utilizando ratos de ambos os gêneros.

\section{AGRADECIMENTOS}

Os autores agradecem a Capes, CNPq e Fapesp, pelo suporte financeiro, ao Profo Ms. Fabricio Azevedo Voltarelli, Clarice Y. Sibuya, José Roberto R. da Silva e Eduardo Custódio, pelo suporte técnico e contribuição no desenvolvimento e execução deste trabalho.

Todos os autores declararam não haver qualquer potencial conflito de interesses referente a este artigo.

\section{REFERÊNCIAS BIBLIOGRÁFICAS}

1. Oliveira AMA, Cerqueira EMM, Souza JS, Oliveira AC. Sobrepeso e obesidade infantil: influência de fatores biológicos e ambientais em Feira de Santana, BA. Arq. Bras. Endocrinol. Metab. 2003, 47:2

2. Dâmaso A. Nutriçăo e exercício na prevençăo de doenças. Rio de Janeiro, 2001, MEDSI.

3. Scalfani A. Animal models of obesity: classification and characterization. Zut. J. of Obes. 1984;8(5):497-508. Review.

4. Marmo MR, Dolnikoff MS, Kettelhut IC, Matsushita DM, Hell NS, Lima FB, et al. Neonatal monosodium glutamate treatment increases epididymal adipose tissue sensitivity to insulin there-month old rats. Braz J Med Biol Res. 1994;27(5):1249-53.

5. De Mello MA, de Souza CT, Braga LR, dos Santos JW, Ribeiro IA,AL Gobatto CA. Glucose tolerance and insulin action in monosodium glutamate (MSG) obese exercise-trained rats. Physiol Chem Phys Med NMR. 2001;33(1):63-71

6. Gobatto CA, Sibuya CY, Azevedo JRM, Luciano E, Kokubun E, Mello MAR. Caracterização da intensidade de exercício e do efeito de treinamento físico no modelo de natação de ratos Wistar. Motriz. 2001;7:557-62.

Voltarelli FA, Gobatto CA, de Mello MA. Determination of anaerobic threshold in rats using the lactate minimum test. Braz J Med Biol Res. 2002;35(11):1389-394.

8. Voltarelli FA, Nunes WMS, Silva ARS, Romero CEM, Garcia DR, Paoll JR, Santhiago V, Gobatto CA, Mello MAR. Determinação do limiar anaeróbio em ratas obesas tratadas com glutamato monossódico [MSG]. Revista Logos. 2003;11:84-92

9. Heck H, Mader A, Hess G, Mucke S, Muller R, Hollmann W. Justification of the 4-mmol/l lactate threshold. Int J Sports Med. 1985;6(3):117-30.

10. Manchado FB, Gobatto CA, Contarteze RVL, Papoti M, Mello, MAR. Maximal lactate steady state in running rats. Journal of exercise physiology online, EUA. 2005;8:29-35.

11. Bernardis LL, Patterson BD. Correlation between "Lee index" and carcass fat content in weanling and adult female rats with hypothalamic lesions. J Endocrinol. 1968:40(4):527-8.

12. Berenson GS, Srinivasan SR, Wattigney WA, Harsha DW. Obesity and cardiovascular risk in children. Ann N Y Acad Sci. 1993,669:93-103.
13. Freedman DS, Jacobsen SJ, Barboriak JJ, Sobocinski KA, Anderson AJ, Kissebah AH, et al. Body fat distribution and male/female differences in lipids and lipoproteins. Circulation. 1990;81(5):1498-506.

14. Björntorp P. Metabolic implications of body fat distribution. Diabetes Care. 1991;14(12):1132-43.

15. Jakicic JM, Donnelly JE, Jawad AF, Jacobsen DJ, Gunderson SC, Pascale R. Association between blood lipids and different measures of body fat distribution: effects of BMl and age. Int J Obes Relat Metab Disord. 1993;17(3):131-7.

16. Rohner F. A neuroendocrine reappraisal of the dual-center hypothesis: its implications for obsity and insulin resistance. Inter. J. of Obes. 1995, 517-534.

7. Tokuyama K, Himms-Hagen J. Brown adipose tissue thermogenesis, torpor, and obesity of glutamate-treated mice Am J Physiol. 1986:251(4 Pt 1):E407-25.

18. Guedes DP, Guedes JERP. Distribuição de gordura corporal, pressão arterial e níveis de lipídios-lipoproteínas plasmáticas. Arq Bras Cardiol. 1998;70(2)

19. Gordon PM, Goss FL, Visich PS, Warty V, Denys BJ, Metz KF, et al. The acute effects of exercise intensity on HDL-C metabolism. Med Sci Sports Exerc. 1994;26(6):671-7.

20. Gobatto CA, Kokubun E, Sibuya CY, Mello MAR. Efeitos da desnutrição protéico-calórica e do treinamento físico na produção de ácido lático em ratos machos adultos após teste de cargas progressivas. Resultados preliminares. Ciência e Cultura, 1991, v. 43, 725-726.

21. Tegtbur U, Busse MW, Braumann KM. Estimation of an individual equilibrium between lactate production and catabolism during exercise. Med Sci Sports Exerc. 1993;25(5):620-7.

22. Remke H, Wilsdorf A, Muller F. Development of hypothalamic obesity in growing rats. Exp Pathol. 1988;33(4):223-32.

23. Braga LR, Mello MAR, Gobatto CA. Exercício contínuo e intermitente: Efeitos do treinamento e do destreinamento sobre peso corporal e metabolismo muscular de ratos obesos. Revista Portuguesa de Ciências do Desporto, Portugal. 2006;6(2). In press. 